\title{
Body Composition and Anthropometric Measures of Footballers, Cup Winners of Montenegro and Bosnia and Herzegovina
}

\author{
Dusko Bjelica', Jovan Gardasevic ${ }^{1}$, Ivan Vasiljevic' ${ }^{1}$, Marin Corluka² \\ 'University of Montenegro, Faculty for Sport and Physical Education, Niksic, Montenegro, ${ }^{2}$ University of Mostar, Faculty of Mathematics and Science \\ Education, Mostar, Bosnia and Herzegovina
}

\begin{abstract}
The aim of this research was to determine the differences among the top football players of the Montenegrin club FC Sutjeska-Niksic and Bosnia and Herzegovina club FC Siroki Brijeg, the Cup winners in their countries, in the anthropometric measures and body composition. A sample of 45 examinees is divided into two sub-samples. The first sub-sample of the examinees consisted of 23 players of FC Sutjeska-Niksic of the average age of 21.69 \pm 4.30 , the champions of the Cup of Montenegro in the season 2016/17, while the other sub-sample consisted of 22 players of FC Siroki Brijeg of the average age of 24.00 6.22 , the champions of the Cup of Bosnia and Herzegovina in the season 2016/17. Football players were tested immediately after the end of the competition season 2016/17. Anthropometric measures in the body composition were evaluated by a battery of 10 variables: body height, body weight, waist size, triceps skin set, biceps skin set, back skin set, abdominal skin set, body mass index, fat percentage and muscle mass. The standard central and dispersive parameters of all variables are calculated. The significance of the differences between the players of the top two football clubs in the anthropometric measures and variables for assessing body composition was determined by a t-test for independent samples. It was found that the football players of the two mentioned clubs don't have statistically significant differences by the variables.
\end{abstract}

Key words: footballers, anthropometric measures, body composition, Montenegro, Bosnia and Herzegovina

\section{Uvod}

Za fudbalsku igru se kaže da je to najvažnija sporedna stvar na svijetu, okuplja velike mase na stadionima, kraj TV ekrana (Gardašević, 2010; Gardašević, Bjelica, Popović, \& Milašinović, 2016). To je izuzetno dinamična i brza kolektivna igra, koja bogatstvom pokreta spada u red polistrukturalnih sportskih igara (Bjelica, 2005; Gardašević i Goranović, 2011; Gardašević i Bjelica, 2013; Gardaševic \& Bjelica, 2014a; Gardasevic i Bjelica, 2014b). Fudbal je sport koga odlikuju mnogobrojne i raznovrsne složene dinamičke kineziološke aktivnosti koje se odlikuju velikim brojem cikličnih (Gardašević, Vasiljević, i Bojanić, 2015; Bjelica, Popović, \& Gardašević, 2016a; Bjelica, Popović, i Gardašević, 2016b; Sermaxhaj, Popovic, Bjelica, Gardasevic, \& Arifi, 2017; Gardasevic,
Bjelica, \& Vasiljevic, 2017a; Gardasevic, Bjelica, \& Vasiljevic, 2017b) i acikličnih kretanja (Gardasevic, 2015; Gardašević i sar., 2015; Gardašević, Bjelica, i Vasiljević, 2016a; Gardašević, Bjelica, i Vasiljević, 2016b; Gardasevic, Bjelica, Milasinovic, i Vasiljevic, 2016; Gardaševic i Vasiljević, 2016; Gardasevic, Popovic, \& Bjelica, 2016). Vrhunski rezultati u fudbalu mogu se postići samo u uslovima programiranog trenažnog procesa (Gardašević, Bjelica, i Popović, 2015). Od poznavanja strukture pojedinih antropoloških sposobnosti i karakteristika fudbalera, kao i njihovog razvoja, zavisi i kvalitetno upravljanje procesom sportskog treninga (Bjelica i Popović, 2012; Bjelica, 2013). Raznim istraživanjima treba utvrditi određene principe i zakonitosti transformacionih procesa antropoloških karakteristika bitnih za fudbal (Gardašević, Bjelica, Georgiev, \&

Correspondence:

Montenegro J.Gardasevic

Gport University of Montenegro, Faculty for Sport and Physical Education, Narodne omladine bb, 81400 Niksic, Montenegro E-mail: jovan@ac.me 
Popović, 2012; Gardasevic, Bjelica, \& Corluka, 2018) a među njima naravno i morfoloških karakteristika. Saznanja o morfološkim karakteristikama važna su u kompleksnim sportskim igrama kao što je fudbal. Morfološki prostor definišu longitudinalna dimenzionalnost skeleta, transverzalna dimenzionalnost skeleta, masa i volumen tela (Bjelica \& Fratrić, 2011). Svrha morfoloških karakteristika je da se poboljšaju vještine u mnogim sportovima (Carter \& Heath, 1990). Morfološki status vrhunskih sportista su relativno homogeni, zavisnosti od sporta, i mogu biti definisan kao modeli sportskog postignuća (Mišigoj-Duraković, Matković, \& Medved, 1995). Istraživanja morfoloških karakteristika među sportistima različitih sportova ukazuju na to da sportisti različitih sportova imaju svoja specifična obilježja. Mišićna masa poboljšava sportsko postignuće u aktivnostima koje zahtevaju mišićnu snagu i izdržljivost ali i u onima koje zahtijevaju zavidnu aerobnu sposobnost (Ramadan \& Byrd, 1987; Green, 1992; Rico-Sanz, 1998). Pripadnost sportiste jednoj sportskoj grani podrazumijeva njegov biotip, koji mu daje prednost da se bavi baš tim sportom u odnosu na druge.

Danas je fudbal sigurno sport broj jedan u svijetu po gledanosti i popularnosti (Gardašević, Georgiev, \& Bjelica, 2012; Vasiljević, Gardašević, \& Bojanić, 2013), pa samim tim i u Crnoj Gori, kao i u zemljama regiona. Jedan od najvećih fudbalskih klubova u Crnoj Gori, po popularnosti, bogatoj istoriji, broju osvojenih trofeja je FK Sutjeska iz Nikšića. U Bosni i Hercegovini je to FK Široki Brijeg. Oni su u odigranoj takmičarskoj sezoni 2016/17., svaki u svojoj državi, osvojili trofej nacionalnog Kupa i stekli pravo igranja na međunarodnoj fudbalskoj sceni u okviru takmičenja pod okriljem UEFA-e. Obzirom da su iz dvije različite, susjedne države, da je fudbal u njima vrlo sličnog kvaliteta, a osvajači su svojih nacionalnih kupova, bili su interesantni istraživačima oko utvrđivanja morfoloških karakteristika i sastava tijela, kao i njihovih međusobnih razlika.

Cilj istraživanja je bio da se analiziraju razlike u pojedinim morfološkim karakteristikama i sastavu tijela između vrhunskih fudbalera ova dva Kluba.

\section{Metod}

Podaci dobijeni u istraživanju morfoloških karakteristika i sastava tijela, kontrolisani su i pripremljeni za obradu u skladu sa postavljenim ciljem. Baze podataka su sređene po praćenim obilježjima i pripremljene za planiranu statističku obradu. Rezultati dobijeni statističkom obradom prikazani su u tabelama i analizirani po pripadajućim logičkim cjelinama. U cjelini posmatrano, prikaz rezultata istraživanja, kroz postupnost u obrazlaganju pojedinačnih veza, omogućava sagledavanje razlika u posmatranim morfološkim mjerama i sastavu tijela, u skladu sa ciljem istraživanja, odnosno doprinosi jasnom određenju prema očekivanoj primjeni dobijenih rezultata u praksi. $\mathrm{U}$ pogledu vremenske određenosti istraživanje je transverzalnog karaktera, a sastoji se u jednokratnom mjerenju odgovarajućih morfoloških karakteristika i sastava tijela vrhunskih fudbalera seniora.

\section{Uzorak ispitanika}

Uzorak ispitanika čini ukupno 45 vrhunskih fudbalera seniorskog pogona dva kluba koji nastupaju u Prvoj fudbalskoj ligi Crne Gore (FK Sutjeska-Nikšić) i u Premijer fudbalskoj ligi Bosne i Hercegovine (FK Široki Brijeg). Prvi subuzorak su činili 23 igrača FK Sutjeska-Nikšić, prosječne starosti
21.69 \pm 4.30 , osvajača Kupa Crne Gore u sezoni 2016/17., a drugi subuzorak su činili 22 igrača FK Široki Brijeg, prosječne starosti $24.00 \pm 6.22$, osvajača Kupa Bosne i Hercegovine za tu istu sezonu. Fudbaleri su testirani neposredno nakon okončanja takmičarske sezone 2016/17.

\section{Uzorak mjera}

Antropometrijsko istraživanje sprovedeno je uz poštovanje osnovnih pravila i principa vezanih za izbor mjernih instrumenata i tehnike mjerenja koji su standardizovani, prema upustvima Internacionalnog Biološkog Programa. Za potrebe ovog istraživanja izmjereno je 7 antropometrijskih mjera: visina tijela (ATV), težina tijela (ATM), obim struka (AOS), kožni nabor tricepsa (ANT), kožni nabor bicepsa (ANB), kožni nabor leđa (ANL), kožni nabor trbuha (ANS), i 3 varijable za procjenu sastava tijela: indeks tjelesne mase (BMI), procenat masti (APM) i mišićna masa (AMM). Za antropometrijsko mjerenje korišćeni su antropometar, kaliper i centimetarska traka. Za procjenu sastava tijela korišćena je tanita vaga, model BC-418MA. Princip rada ove vage je zasnovan na indirektnom mjerenju tjelesnog sastava, bezbjedan električni signal se šalje kroz tijelo preko elektroda smještenih u samostalnu jedinicu. Tanita vaga, zahvaljujući atletskom modu koje posjeduje, omogućava sportistima detaljno praćenje tjelesne težine, zdrastvenog stanja i kondicije, sa svim relevantnim parametrima.

\section{Metode obrade podataka}

Podaci dobijeni istraživanjem obrađeni su postupcima deskriptivne i komparativne statističke procedure. Za svaku varijablu su obrađeni centralni i disperzioni parametri kao i mjere asimetrije i spljoštenosti. Razlike u morfološkim karateristikama i sastavu tijela fudbalera ova dva Kluba utvrđene su primjenom diskriminativne parametrijske procedure, Studentovim t-testom za male nezavisne uzorke, sa statističkom značajnošću od $\mathrm{p}<0.05$.

\section{Rezultati}

U Tabelama 1. i 2. prikazani su osnovni deskriptivni statistički parametri antropometrijskih varijabli i sastava tijela fudbalera dva Kluba, gdje su izračunate vrijednosti mjera centralne i disperzione tendencije i to: aritmetička sredina (Mean), standardna devijacija (Std. Dev.), varijansa (Variance), minimalne (Min) i maksimalne (Max) vrijednosti, koeficijenti zakrivljenosti (Skewness) i izduženosti (Kurtosis). Prvo su analizirani centralni i disperzioni parametri varijabli za procjenu morfoloških karakteristika i sastava tijela igrača FK Sutjeska-Nikšić (Tabela 1.).

Na osnovu centralnih i disperzionih parametara, vrijednosti skjunisa i kurtozisa možemo konstatovati da su sve varijable u granicama normalne raspodjele. Vidi se po vrijednosti skjunisa da dvije varijable: nabor bicepsa (ANB) i nabor leđa (ANL) imaju blagu asimetriju, ne i statistički značajnu u stranu boljih rezultata iako imaju pozitivan predznak, jer je za fudbalere bitno da imaju manje vrijednosti potkožnog masnog tkiva. Po vrijednosti kurtozisa se vide tri varijable tjelesna masa (ATM), indeks tjelesne mase (BMI) i mišićna masa (AMM) koje imaju blagu platikurtičnost ne i statistički značajnu, što znači da postoje različiti rezultati u ovim varijablama koji nijesu raspoređeni oko aritmetičke sredine, najvjerovatnije iz razloga da po linijama tima igrači (golmani, odbrana, vezni red i napadači) imaju različitu konstituciju i samim tim tjelesnu masu, što se i odrazilo na ove varijable. Generalno, na osnovu 
Tabela 1. Centralni i disperzioni parametri varijabli za procjenu morfoloških karakteristika i sastava tijela igrača FK Sutjeska-Nikšić ( $N=23$ )

\begin{tabular}{|c|c|c|c|c|c|c|c|c|c|}
\hline \multirow{2}{*}{ variable } & \multirow{2}{*}{ Min } & \multirow{2}{*}{ Max } & \multirow{2}{*}{ Mean } & \multirow{2}{*}{ Std.D. } & \multirow{2}{*}{ Variance } & \multicolumn{2}{|c|}{ Skewness } & \multicolumn{2}{|c|}{ Kurtosis } \\
\hline & & & & & & Stat. & Std. E. & Stat. & Std. E. \\
\hline ATV & 166.0 & 195.0 & 182.991 & 6.7696 & 45.828 & -.555 & .481 & .607 & .935 \\
\hline ATM & 68.0 & 91.7 & 78.326 & 7.7094 & 59.435 & .480 & .481 & -1.165 & .935 \\
\hline AOS & 76.0 & 90.0 & 83.000 & 3.8258 & 14.636 & .283 & .481 & -.540 & .935 \\
\hline ANT & 3.4 & 9.8 & 6.465 & 1.6648 & 2.771 & .262 & .481 & -.222 & .935 \\
\hline ANB & 3.1 & 7.7 & 4.522 & 1.2232 & 1.496 & 1.116 & .481 & .945 & .935 \\
\hline ANL & 6.4 & 11.8 & 8.130 & 1.4198 & 2.016 & 1.105 & .481 & 1.153 & .935 \\
\hline ANS & 5.4 & 14.0 & 8.248 & 2.3766 & 5.648 & .846 & .481 & .032 & .935 \\
\hline BMI & 21.7 & 25.8 & 23.361 & 1.4125 & 1.995 & .435 & .481 & -1.329 & .935 \\
\hline APM & 2.6 & 13.6 & 8.657 & 2.9212 & 8.533 & -.380 & .481 & -.512 & .935 \\
\hline AMM & 34.1 & 46.8 & 40.565 & 3.8087 & 14.506 & -.026 & .481 & -1.198 & .935 \\
\hline
\end{tabular}

svih statističkih parametara, može se konstatovati da se radi o vrhunskim fudbalerima, da u svim varijablama postoji normalan raspored i da preovladavaju rezultati bolji od aritmetičke sredine, ne i statistički značajni jer je i za očekivati da kod fudbalera jednog profesionalnog kluba nema prevelikog raspona u rezultatima analiziranih varijabli.

Tabela 2. Centralni i disperzioni parametri varijabli za procjenu morfoloških karakteristika i sastava tijela igrača FK Široki Brijeg (N=22)

\begin{tabular}{cccccccccc}
\hline variable & \multirow{2}{*}{ Min } & \multirow{2}{*}{ Max } & \multirow{2}{*}{ Mean } & \multirow{2}{*}{ Std.D. } & Variance & \multicolumn{2}{c}{ Skewness } & \multicolumn{2}{c}{ Kurtosis } \\
Stat. & Std. E. & Stat. & Std. E. \\
\hline ATV & 167.2 & 195.5 & 183.286 & 6.75 & 45.59 & -.59 & .49 & .34 & .95 \\
ATM & 64.6 & 87.9 & 77.600 & 6.57 & 43.12 & -.46 & .49 & -.52 & .95 \\
AOS & 78.0 & 92.0 & 83.773 & 3.84 & 14.75 & .59 & .49 & .14 & .953 \\
ANT & 4.0 & 9.2 & 5.877 & 1.17 & 1.37 & 1.06 & .49 & 1.81 & .95 \\
ANB & 3.6 & 6.6 & 4.577 & .75 & .57 & 1.00 & .49 & 1.01 & .95 \\
ANL & 6.6 & 13.6 & 8.959 & 1.75 & 3.05 & .92 & .49 & 1.14 & .95 \\
ANS & 4.8 & 13.6 & 8.509 & 2.49 & 6.19 & .45 & .49 & -.69 & .95 \\
BMI & 20.7 & 26.8 & 22.991 & 1.51 & 2.28 & .37 & .49 & .34 & .95 \\
APM & 4.2 & 14.5 & 9.841 & 2.69 & 7.22 & -.38 & .49 & -.18 & .95 \\
AMM & 33.1 & 46.1 & 39.573 & 3.26 & 10.61 & -.17 & .49 & .23 & .95 \\
\hline
\end{tabular}

Tabela 2. prikazuje centralne i disperzione parametre varijabli za procjenu morfoloških karakteristika i sastava tijela igrača FK Široki Brijeg.
Na osnovu centralnih i disperzionih parametara, vrijednosti skjunisa i kurtozisa igrača FK Široki Brijeg, može se konstatovati da su sve varijable u granicama normalne raspodjele

Tabela 3. Vrijednosti t-testa izmedju aritmetičkih sredina varijabli za procjenu morfoloških karakteristika i sastava tijela igrača FK Sutjeska-Nikšić i FK Široki Brijeg

\begin{tabular}{|c|c|c|c|c|c|c|c|c|}
\hline varijable & klub & $\mathbf{N}$ & Mean & Std. D. & Std.E.M. & t-test & Sig. & Mean Difference \\
\hline \multirow[b]{2}{*}{ ATV } & SUT & 23 & 182.991 & 6.769 & 1.4116 & \multirow[b]{2}{*}{-.146} & \multirow[b]{2}{*}{.884} & \multirow{2}{*}{-.295} \\
\hline & ŠIR & 22 & 183.286 & 6.751 & 1.4395 & & & \\
\hline \multirow{2}{*}{ ATM } & SUT & 23 & 78.326 & 7.709 & 1.6075 & \multirow{2}{*}{.341} & \multirow{2}{*}{.735} & \multirow{2}{*}{.726} \\
\hline & ŠIR & 22 & 77.600 & 6.566 & 1.4000 & & & \\
\hline \multirow{2}{*}{ AOS } & SUT & 23 & 83.000 & 3.825 & .7977 & \multirow{2}{*}{-.676} & \multirow{2}{*}{.503} & \multirow{2}{*}{-.773} \\
\hline & ŠIR & 22 & 83.773 & 3.841 & .8190 & & & \\
\hline \multirow{2}{*}{ ANT } & SUT & 23 & 6.465 & 1.664 & .3471 & \multirow{2}{*}{1.375} & \multirow{2}{*}{.177} & \multirow{2}{*}{.588} \\
\hline & ŠIR & 22 & 5.877 & 1.171 & .2497 & & & \\
\hline \multirow{2}{*}{ ANB } & SUT & 23 & 4.522 & 1.223 & .2551 & \multirow{2}{*}{-.184} & \multirow{2}{*}{.855} & \multirow{2}{*}{-.055} \\
\hline & ŠIR & 22 & 4.577 & .753 & .1606 & & & \\
\hline \multirow{2}{*}{ ANL } & SUT & 23 & 8.130 & 1.419 & .2961 & \multirow[b]{2}{*}{-1.742} & \multirow{2}{*}{.089} & \multirow{2}{*}{-.829} \\
\hline & ŠIR & 22 & 8.959 & 1.745 & .3722 & & & \\
\hline \multirow{2}{*}{ ANS } & SUT & 23 & 8.248 & 2.376 & .4955 & \multirow[b]{2}{*}{-.360} & \multirow[b]{2}{*}{.721} & \multirow{2}{*}{-.261} \\
\hline & ŠIR & 22 & 8.509 & 2.487 & .5304 & & & \\
\hline \multirow{2}{*}{ BMI } & SUT & 23 & 23.361 & 1.412 & .2945 & \multirow{2}{*}{.847} & \multirow{2}{*}{.402} & \multirow{2}{*}{.370} \\
\hline & ŠIR & 22 & 22.991 & 1.511 & .3223 & & & \\
\hline \multirow{2}{*}{ APM } & SUT & 23 & 8.657 & 2.921 & 6091 & \multirow{2}{*}{-1.416} & 161 & 1181 \\
\hline & ŠIR & 22 & 9.841 & 2.687 & .5730 & & .164 & -1.184 \\
\hline & SUT & 23 & 40.565 & 3.808 & .7942 & & & \\
\hline AMM & ŠIR & 22 & 39.573 & 3.257 & 6944 & .941 & .352 & .992 \\
\hline
\end{tabular}


i da su vrijednosti vrlo slične fudbalerima FK Sutjeska-Nikšić. Takođe se može konstatovati da su igrači FK Široki Brijeg u prosjeku stariji, nešto malo visočiji i manje tjelesne težine od igrača FC Sutjeska-Nikšić, kao i da imaju veći procenat masti u organizmu a manju mišićnu masu, istina neznatno, međutim da li i statistički značajno to će pokazati komparativna statistička procedura, t-test (Tabela 3.). Po vrijednosti skjunisa vidi se da je kod varijabli nabor tricepsa (ANT) i nabor bicepsa (ANB) došlo do male nagnutosti u stranu manjih rezultata što je dobro jer je potkožno masno tkivo remeteći faktor za profesionalne sportiste. Vrijednosti kurtozisa kod varijabli nabor tricepsa (ANT), nabor bicepsa (ANB) i nabor leđa (ANL) obrazuju blagu leptokurtičnu krivu što govori o priličnoj ujednačenosti igračkog kadra FK Široki Brijeg u ove tri varijable.

Da bi se moglo utvrditi da li ima statistički značajne razlike $\mathrm{u}$ analiziranim varijablama kod vrhunskih fudbalera ova dva Kluba, primjenjena je statistička procedura t-test (Tabela 3.).

$\mathrm{Na}$ osnovu dobijenih vrijednosti rezultata t-testa, može se primijetiti da ne postoje statistički značajne razlike ni kod jedne varijable na nivou značajnosti $\mathrm{p}<0.05$. Može se primijetiti da fudbaleri FK Sutjeska iz Nikšića imaju neznatno bolje rezultate u većini tretiranih varijabli od fudbalera FK Široki Brijeg, međutim ne i statistički značajno.

\section{Diskusija}

Cilj ovog istraživanja je bio da se utvrdi razlika u antropometrijskim karakteristikama i sastavu tijela vrhunskih igrača dva ponajbolja fudbalska kluba u svojim državama, FK Sutjeska-Nikšić iz Crne Gore i FK Široki Brijeg iz Bosne i Hercegovine. Veoma je bila zanimljiva ideja uporediti fudbalere iz susjednih država koji su nekada igrali u zajedničkoj ligi, kakav je sada njihov odnos i eventualna razlika u pomenutim prostorima, obzirom da su $\mathrm{u}$ istoj takmičarskoj sezoni osvojili isti trofej, naravno svako u svojoj državi. Uzorak od ukupno 45 ispitanika je podijeljen na dva subuzorka. Prvi subuzorak ispitanika su činili 23 igrača FK Sutjeska-Nikšić prosječne starosti $21.69 \pm 4.30$ godina, osvajača Kupa Crne Gore u sezoni 2016/17., a drugi subuzorak su sačinjavali 22 igrača FK Široki Brijeg prosječne starosti $24.00 \pm 6.22$ godina, osvajača Kupa Bosne i Hercegovine u sezoni 2016/17. Igrači FK Sutjeska-Nikšić su u prosjeku bili mlađi od fudbalera FK Široki Brijeg, međutim ne i statistički značajno. Rezultati su dobijeni korišćenjem baterije od 10 testova u prostoru antropometrijskih karakteristika i sastava tijela. Uvidom u osnovne deskriptivne statističke parametre se može zaključiti da se radi o profesionalnim sportistima i da su njihovi rezultati vrlo slični rezultatima fudbalerima koji igraju u istim ligama (Corluka \& Vasiljevic, 2018; Gardasevic, Bjelica, Popovic, Vasiljevic, \& Milosevic, 2018; Bjelica, Gardasevic, \& Vasiljevic, 2018) ili u regionu (Gardasevic, Bjelica, Vasiljevic, Sermaxhaj, \& Arifi, 2018; Corluka et al., 2018). Vidi se da su igrači oba kluba približnih srednjih vrijednosti analiziranih varijabli, što i ne čudi jer se radi o dva ponajbolja kluba u Crnoj Gori i Bosni i Hercegovini gdje je i koncentracija najboljih igrača najveća. Ovim je potvrđena hipoteza da je kvalitet igrača fudbala vrlo sličan u regionu. Prosječna tjelesna visina oba kluba odgovara i rezultatima istraživanja (Bjelica et al, 2012; Popovic, Bjelica, Tanase, \& Milasinovic, 2015) gdje je ukupan broj stanovnika i u Crnoj Gori i u Bosni i Hercegovini među najvišim u Evropi. Rezultati t-testa nijesu pokazali postojanje statistički značajne razlike ni kod jedne analizirane varijable. Uvidom u tabele, evidentno je da igrači FK Sutjeska-Nikšić imaju manje vrijed- nosti potkožnih nabora kao i procenat masti od fudbalera FK Široki Brijeg, međutim te razlike nijesu statistički značajne, a može se zaključiti da su procenti masti kod svih fudbalera u okvirima normativnih vrijednosti procenata masti koje iznose od $6-13 \%$. Treneri obje ekipe mogu biti zadovoljni sa stanjem svojih igrača u pomenutim varijablama, međutim sigurno da i tu može doći do određenog poboljšanja. Takođe, u oba kluba bi se trebali posvetiti i drugim istraživanjima i provjeriti stanje funkcionalno-motoričkog statusa, psihološkog profila svojih fudbalera, kao i taktičke obučenosti i analizirati da li tu leži razlog slabijeg rezultata na međunarodnoj sceni, jer ovi klubovi kao i većina ostalih iz regiona ne pravi iole značajnije rezultate u evropskim takmičenjima. Rezultati koji su dobijeni ovim istraživanjem mogu poslužiti kao modelni parametri u procjenjivanim varijablama za sve ostale igrače fudbalskih klubova u Crnoj Gori i Bosni i Hercegovini, jer analizirani fudbaleri igraju za dva velika kluba u svojim državama, samim tim su među najboljim i najuspješnijim u njima.

\section{Acknowledgements}

There are no acknowledgements.

\section{Conflict of Interest}

The authors declare that there are no conflicts of interest.

Received: 25 September 2018 | Accepted: 13 October 2018 | Published: 29 October 2018

\section{References}

Bjelica, D. (2005). Sistematizacija sportskih disciplina i sportski trening. Podgorica: Crnogorska sportska akademija.

Bjelica, D. (2013). Teorija sportskog treninga. Podgorica: Univerzitet Crne Gore.

Bjelica, D., \& Fratrić, F. (2011). Sportski trening: teorija, metodika i dijagnostika. Nikšić: Fakultet za sport i fizičko vaspitanje.

Bjelica, D., i Popović, S. (2012). Fudbal-teorija, tehnika i taktika. Podgorica: Crnogorska sportska akademija.

Bjelica, D., Popovic, S., Kezunovic, M., Petkovic, J., Jurak, G., \& Grasgruber, P. (2012). Body Height and Its Estimation Utilizing Arm Span Measurements in Montenegrin Adults. Anthropological Notebooks, 18(2),69-83.

Bjelica, D., Popović, S., i Gardašević, J. (2016a). Modeli fizičke pripreme vrhunskih sportaša i doziranje opterećenja. Zbornik radova 14. godišnje međunarodne konferencije "Kondicijska priprema sportaša" (185-189), Zagreb: Udruga kondicijskih trenera Hrvatske.

Bjelica, D., Popović, S., i Gardašević, J. (2016b). Opći principi planiranja i programiranja fizičkih priprema sportaša. Zbornik radova 14. godišnje međunarodne konferencije "Kondicijska priprema sportaša" (190-192), Zagreb: Udruga kondicijskih trenera Hrvatske.

Bjelica, D., Gardasevic, J., \& Vasiljevic, I. (2018). Differences in the morphological characteristics and body composition of football players FC Sutjeska and FC Mladost in Montenegro. Journal of Anthropology of Sport and Physical Education, 2(2), 31-5. doi: 10.26773/jaspe.180406

Carter, J.E.L., \& Heath, B.H. (1990). Somatotyping-Development and application. Cambridge, United Kingdom: Cambridge University Press.

Corluka, M., Bjelica, D., Vasiljevic, I., Bubanja, M., Georgiev, G., \& Zeljko, I. (2018). Differences in the morphological characteristics and body composition of football players of hsc zrinjski mostar and fc siroki brijeg in bosnia and herzegovina. Sport Mont, 16(2), 77-81. doi: 10.26773/ smj. 180614

Corluka, M., \& Vasiljevic, I. (2018). Differences in the morphological characteristics and body composition of football players in Montenegro. Journal of Anthropology of Sport and Physical Education, 2(1), 3-7. doi: 10.26773 /jaspe. 180101

Gardašević, J. (2010). Efekti programiranog rada u pripremnom periodu na transformaciju bazično-motoričkih i situaciono-motoričkih sposobnosti kod fudbalera kadetskog uzrasta. Neobjavljena magistarska teza. Nikšić: Fakultet za sport i fizičko vaspitanje.

Gardašević, J., i Goranović, K. (2011). Efekti programiranog rada u pripremnom periodu na transformaciju eksplozivne snage kod fudbalera kadeta. Sport Mont, 9(28-30), 55-62.

Gardašević, J., Georgiev, G., \& Bjelica, D. (2012). Qualitative changes of basic motor abilities after completing a six-week training programme. Acta 
Kinesiologica, 6(1), 70-4.

Gardašević, J., Bjelica, D., Georgiev, G., \& Popović, S. (2012). Transformation of situational motor abilities with football players-cadets. Proceeding book, XVI International Scientific Congress "Olympic Sports and Sport for All" \& VI International Scientific Congress "Sport, Stress, Adaptation" (373377), Sofia: National Sports Academy "Vassil Levski".

Gardašević, J., i Bjelica, D. (2013). Efekti programiranog trenažnog rada u trajanju od šest nedjelja na transformaciju fleksibilnosti kod fudbalera kadetskog uzrasta. Sport Mont, 11(37-39), 212-7.

Gardaševic, J., \& Bjelica, D. (2014a). The effects of the training in the preparation period on the dribbling speed with fifteen years old football players. Book of Abstracts of the 11th International Scientific Conference on Transformation Process in Sport "Sport Performance" (22-23), Podgorica: Montenegrin Sports Academy.

Gardasevic, J., i Bjelica, D. (2014b). Efekti rada u pripremnom periodu na brz inu vođenja lopte petnaestogodišnjih fudbalera. Sport Mont, 12(40-42), 160-6.

Gardašević, J., Vasiljević, I., \& Bojanić, D. (2015). Six-week preparation period and its effects on coordination transformation with football players under 16. Book of Abstracts 11th International Scientific Conference Management, Sport, Olympism (36), Beograd: Fakultet za menadžment u sportu, Alfa univerzitet.

Gardasevic, J. (2015). The effects of the training in the preparation period on the agility transformation with cadet level football players. Book of Abstracts of the 12th International Scientific Conference on Transformation Process in Sport "Sport Performance" (76-77), Podgorica: Montenegrin Sports Academy.

Gardašević, J., Vasiljević, I., Bojanić, D., Muratović, A., Ljubojević, M., Milašinović, R., \& Bubanja, M. (2015). Six-week Preparation Period and its Effects on Transformation Movement Speed with Football Players Under 16. Book of Abstracts, International Scientific Conference "Effects of Physical Activity Application to Anthropological Status with Children, Youth and Adults" (148), Belgrade:University of Belgrade: Faculty of Sport and Physical Education.

Gardašević, J., Bjelica, D., i Popović S. (2015). Efekti programiranog rada tokom pripremnog perioda na transformaciju agilnosti kod fudbalera kadetskog uzrasta. Sport Mont, 13(43-45), 355-60.

Gardašević, J., Bjelica, D., \& Vasiljević, I. (2016a). Six-Week Preparation Period and its Effects on Transformation Movement Speed with Football Players Under 16. Sport Mont, 14(1), 13-6.

Gardašević, J., Bjelica, D., \& Vasiljević, I. (2016b). The Effects of the Training in the Preparation Period on the Repetitive Strength Transformation With Cadet Level Football Players. Book of Abstracts of the 13th International Scientific Conference on Transformation Processes in Sport "Sport Performance" (43), Podgorica: Montenegrin Sports Academy.

Gardasevic, J., Bjelica, D., Milasinovic, R., \& Vasiljevic, I. (2016). The Effects of the Training in the Preparation Period on the Repetitive Strength Transformation with Cadet Level Football Players. Sport Mont, 14(2), 31-3.

Gardaševic, J., \& Vasiljević, I. (2016). Effects of Preparation Period on Endurance in U16 Football Players. Book of Abstracts of the $4^{\text {Th }}$ International Scientific Conference "Exercise and Quality of Life" (108), Novi
Sad: University of Novi Sad, Faculty of Sport and Physical Education. Gardašević, J., Bjelica, D., Popović, S., \& Milašinović, R. (2016). Preparation Period and its Effects on the Speed of Ball Leading at Players U16. In Book of Summaries of 11th FIEP European Congress "Anthropological Aspects of Sport, Physical Education and Recreation" (30-31), Banjaluka: University of Banjaluka, Faculty of Physical Education and Sport.

Gardasevic, J., Popovic, S., \& Bjelica, D. (2016). After preparation period ball shooting accuracy at players U15. In Abstract Book of the 8th Conference for Youth Sport (88), Ljubljana: University of Ljubljana, Faculty of Sport.

Gardasevic, J., Bjelica, D., \& Vasiljevic, I. (2017a). The strength of kicking the ball after preparation period with $\mathrm{U} 15$ football players. Book of Abstracts of the 14th International Scientific Conference on Transformation Processes in Sport "Sport Performance" (65-66), Podgorica: Montenegrin Sports Academy.

Gardasevic, J., Bjelica, D., \& Vasiljevic, I. (2017b). The Strength of Kicking the Ball after Preparation Period with U15 Football Players. Sport Mont, 15(2), 39-42.

Gardasevic, J., Bjelica, D., \& Corluka, M. (2018). The impact of the preparation period on endurance at football players U16. Sport Mont, 16(1), 21-4. doi: 10.26773/smj.180204

Gardasevic, J., Bjelica, D., Popovic, S., Vasiljevic, I., \& Milosevic, Z. (2018). Differences in the morphological characteristics and body composition of football players FC Buducnost and FC Mladost in Montenegro. Journal of Anthropology of Sport and Physical Education, 2(1), 51-5. doi: 10.26773/jaspe.180109

Gardasevic, J., Bjelica, D., Vasiljevic, I., Sermaxhaj, S., \& Arifi, F. (2018) Differences in the morphological characteristics and body composition of football players FC Trepca ' 89 and FC Prishtina in Kosovo. Journal of Anthropology of Sport and Physical Education, 2(3), 105-109. doi: 10.26773/jaspe. 180718

Green, S. (1992). Anthropometric and physiological characteristics of south Australian soccer players. Australian Journal of Science and Medicine in Sport, 24, 3-7.

Mišigoj-Duraković, M., Matković, B., \& Medved, R. (1995). Morfološka antropometrija $u$ športu. Morphological anthropometry in sports. Zagreb, Croatia: Fakultet za fizičku kulturu.

Popovic, S., Bjelica, D., Tanase, G.D., \& Milasinovic, R. (2015). Body Height and Its Estimation Utilizing Arm Span Measurements in Bosnian and Herzegovinian Adolescents. Montenegrin Journal of Sports Science and Medicine, 4(1), 29-36.

Ramadan, J., \& Byrd, R. (1987). Physical characteristics of elite soccer players. Journal of Sports Medicine and Physical Fitness, 27, 424-8.

Rico-Sanz, J. (1998). Body composition and nutritional assessments in soccer. International Journal of Sport Nutrition, 8, 113-23.

Sermaxhaj, S., Popovic, S., Bjelica, D., Gardasevic, J., \& Arifi, F. (2017). Effect of recuperation with static stretching in isokinetic force of young football players. Journal of Physical Education and Sport, 17(3), 1948-53. doi: 10.7752/jpes.2017.03191

Vasiljević, I., Gardašević, J., i Bojanić, D. (2013). Uporedna analiza motoričkog prostora između aktivnih fudbalera kadetskog uzrasta i učenika srednje škole. Zbornik naučnih i stručnih radova VI međunarodni simpozijum "Sport i zdravlje" (212-215), Tuzla: Fakultet za tjelesni odgoj i sport. 